\title{
Evaluasi Sistem Pembebanan Sistem Kelistrikan Gedung Fakultas Ekonomi Universitas Lancang Kuning
}

\author{
Abrar Tanjung ${ }^{1}$, Zulfahri $^{1}$ \\ ${ }^{1}$ Teknik Elektro, Fakultas Teknik, Universitas Lancang Kuning \\ J1. Yos Sudarso Km. 8 Rumbai, Pekanbaru, telp. (0761) 52324 \\ Email : abrar@unilak.ac.id, zulfahri@unilak.ac.id
}

\begin{abstract}
ABSTRAK
Saluran energi listrik kebutuhan yang utama dalam kehidupan sehari-hari maupun untuk kebutuhan industri. Disebabkan saluran energi listrik mudah untuk dikirim dan dikonversikan ke dalam bentuk energi lain. Penyediaan energi listrik stabil dan kontinyu syarat mutlak yang harus dipenuhi dalam memenuhi kebutuhan tenaga listrik. Gedung Fakultas Ekonomi terdiri dari dua gedung dua lantai yang di gunakan untuk kegiatan akademik, administrasi dan perkuliahan. Penggunaan ruangan di lengkapi dengan peralatan - peralatan listrik, seperti pemasangan Air Conditioner, lampu penerangan, computer, infocus dan peralatan tambahan lainnya. Akibat pemasangan peralatan listrik tersebut menyebabkan gangguan dan permasalahan pada sistem kelistrikan Gedung Fakultas Ekonomi. Penelitian ini dilakukan untuk mengevaluasi Pembebanan Gedung Fakultas Ekonomi Universitas Lancang Kuning. Berdasarkan hasil pembahasan diperoleh evaluasi pada gedung Fakultas Ekonomi Unilak besar arus rata rata pada tegangan 3 phasa 380 volt sebesar 51,3 amper, besar kapasitas daya sebesar 197 $\mathrm{kW}$, besar jatuh tegangan sebesar 24,1 volt, besar rugi daya sebesar 908,8,89 watt (0,909 kW) dan besar nilai tahanan pentanahan sebesar 22,15 ohm.
\end{abstract}

Kata Kunci : energi listrik, evaluasi pembebanan, tahanan pentanahan

\begin{abstract}
Electrical energy lines are the main needs in everyday life and for industrial needs. Because electrical energy channels are easy to send and convert into other forms of energy. The supply of stable and continuous electrical energy is an absolute requirement that must be met in meeting the needs of electric power. The Faculty of Economics building consists of two two-story buildings that are used for academic, administrative and lecture activities. The use of the room is equipped with electrical equipment, such as installation of air conditioners, lighting, computers, infocus and other additional equipment. As a result of the installation of electrical equipment, it caused disturbances and problems in the electrical system in the Economics Faculty Building. This research was conducted to evaluate the Building Load for the Faculty of Economics, University of Lancang Kuning. Based on the results of the discussion, an evaluation was obtained at the Unilak Faculty of Economics building, the average current at 3 phase 380 volts was 51.3 amps, the power capacity was $197 \mathrm{~kW}$, the voltage drop was 24.1 volts, the power loss was 908.8, 89 watts $(0.909 \mathrm{~kW})$ and the value of grounding resistance is $22.15 \mathrm{ohms}$.
\end{abstract}

Keywords: electrical energy, loading evaluation, grounding resistance

\section{Pendahuluan}

Energi listrik stabil dan kontinyu syarat mutlak yang harus dipenuhi dalam memenuhi kebutuhan tenaga listrik, umumnya menunjukkan peningkatan, karena tenaga listrik merupakan bentuk energi sangat menguntungkan dan membantu manusia dalam melaksanakan kehidupannya. Kebutuhan energi listrik berasal dari pembangkit energi listrik menuju ke pemakai diperlukan sistem jaringan dan gardu distribusi [1]. Gedung Fakultas Ekonomi terdiri dari dua gedung dua lantai yang di gunakan untuk kegiatan akademik, administrasi dan perkuliahan. Penggunaan ruangan di lengkapi dengan peralatan - peralatan listrik, seperti pemasangan Air Conditioner, lampu penerangan, computer, infocus dan peralatan tambahan lainnya. Akibat pemasangan peralatan 
listrik tersebut menyebabkan gangguan dan permasalahan pada sistem kelistrikan Gedung Fakultas Ekonomi. Penggunaan energi listrik umumnya menunjukkan peningkatan, karena tenaga listrik merupakan bentuk energi sangat menguntungkan dan membantu manusia dalam melaksanakan kehidupannya. Oleh karena itu factor kenyamanan dan keamanan sangat harus diperhatikan ketika melakukan pemasangan instalasi listrik di bangunan gedung, sehingga dalam penggunaanya tidak menimbulkan masalah.

\section{Metodologi Penelitian}

Pemakaian arus beban pada gedung I besar arus beban 8,22 amper, gedung II 10,24 amper dan gedung III 1,57 amper. Sedangkan rugi daya pada gedung I sebesar 35,61 watt, gedung II 55,26 watt dan gedung III 1,31 watt. Untuk sistem pentahanan besar nilai tahanan pentanahan pada gedung I 59, $5 \mathrm{ohm}$, gedung II 178 ohm dan gedung III 119 ohm [2][4]. Hasil perhitungan nilai pentanahan peralatan transformator distribusi diperoleh sebesar 22,15 ohm, besar arus gangguan hubung singkat pada transformator distribusi 1,15 amper, kenaikan tegangan phasa sehat diperoleh untuk transformator distribusi sebesar 308 volt, tegangan sentuh 288, 1 volt dan tegangan langkah sebesar 938 volt, besar rugi-rugi daya akibat arus netral sebesar 111,62 watt [3][5].

Drop tegangan sebagian besar melebihi batas toleransi yaitu 5\%, serta daya dan arus yang sudah tidak seimbang lagi [6]. Kemudian pengecekan parameter diperoleh hasil bahwa kondisi fisik dari pengaman tersebut ada sekitar $60 \%$ dari total keseluruhan pengaman dalam kondisi kaku, berkarat, getas, serta jumlah lampu yang terpasang tidak sesuai dengan kebutuhan ruangan sehingga tidak dapat memenuhi lumen lampu yang distandarisasi Persyaratan Umum Instalasi Listrik (PUIL 2011) [7]. Untuk menyeimbangkan beban maka perlu adanya penambahan beban pada fasa R sebesar 690 watt besar pengaman 3.92 A. Pada phasa $\mathrm{S}$ terjadi penurunan daya sebesar 690 watt, besar pengaman 3.92 A. Pada phasa $\mathrm{T}$ penurunan daya sebesar 800 watt, besar pengaman 4.54 A. Adapun kebutuhan maksimum setiap fasa sebesar, fasa $R=33,35 \mathrm{~A}$, fasa $\mathrm{S}=37,92$ $\mathrm{A}$, fasa $\mathrm{T}=36,47 \mathrm{~A}[\mathrm{~b}]$. Issact menunjukkan bahwa $90 \%$ dari sembilan model teratas yang digunakan dalam peramalan listrik berbasis kecerdasan buatan, dengan jaringan saraf tiruan (JST) mewakili $28 \%$. Dalam lingkup ini, model JST terutama digunakan untuk peramalan listrik jangka pendek di mana pola konsumsi energi listrik rumit. Mengenai metrik akurasi yang digunakan, diamati bahwa root-meansquare error (RMSE) (38\%) adalah metrik kesalahan yang paling banyak digunakan di antara peramal kelistrikan, diikuti oleh rata-rata persentase kesalahan MAPE (35\%) [11].

\section{Tegangan Jatuh}

Tegangan jatuh pada saluran tenaga listrik secara umum berbanding lurus dengan panjang saluran dan beban serta berbanding terbalik dengan luas penampang penghantar [9]. Penurunan persamaan tegangan jatuh ditentukan dari gambar diagram fasor transmisi daya pada gambar 1 .

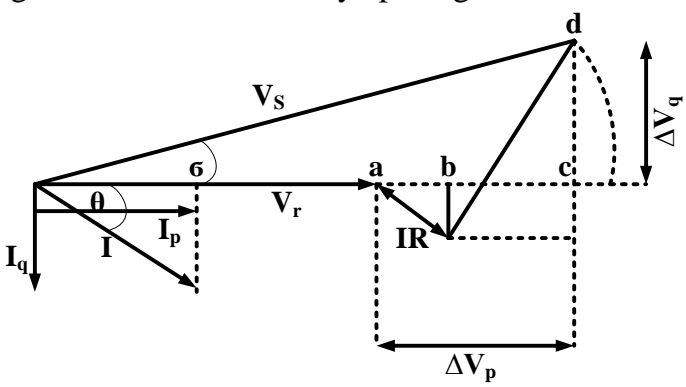

Gambar 1 Diagram Fasor Transmisi Daya Beban Seri

persamaan 1 .

Drop tegangan dapat di tunjukkan pada

$\Delta \mathrm{V}=\mathrm{I} \times \mathrm{Z}$

Drop Tegangan selisih antara tegangan kirim $\left(V_{S}\right)$ dengan tegangan terima $\left(V_{R}\right)$, maka didefinisikan dalam persamaan 2

$$
\Delta \mathrm{V}=\mathrm{V}_{\mathrm{S}} \mathrm{x} \mathrm{V}_{\mathrm{R}}
$$

\section{Rugi-Rugi Daya}

Besar daya listrik yang hilang pada suatu saluran, yang besarnya sama dengan daya yang disalurkan dari sumber dikurangi besarnya daya yang diterima. Pemilihan jenis kabel penghantar jaringan distribusi merupakan faktor penting yang diperhatikan dalam perencanaan dari suatu sistem tenaga listrik [9]. Jenis kabel penghantar dengan nilai tahanan yang kecil dapat memperkecil rugi-rugi daya. Besar rugirugi daya pada jaringan distribusi dapat ditulis sebagai berikut:

$$
\Delta P=I^{2} \cdot R \text { (watt) }
$$

Untuk rugi-rugi daya pada jaringan tiga fasa dinyatakan oleh persamaan:

$$
\begin{gathered}
\Delta P=\sqrt{3} \cdot I^{2} \cdot R \text { (watt) } \\
I=\frac{P}{\sqrt{3} V I \cos \varphi} \text { (ampere) } \\
\text { Daya pada saluran } 3 \text { phasa adalah: } \\
P=\sqrt{3} V I \operatorname{Cos} \varphi \text { (watt) }
\end{gathered}
$$


Tegangan berpengaruh terhadap rugi-rugi daya, semakin besar tegangan pada suatu saluran, maka semakin kecil arus pada saluran tersebut. Sedangkan arus adalah salah satu faktor yang mempengaruhi besar kecilnya rugi-rugi daya pada suatu saluran.

Beban arus seimbang tegangan 3 phasa (380 volt) pada persamaan 7 dibawah ini :

$$
\text { I Rata }- \text { rata }=\frac{I_{R T}+I_{T S}+I_{T R}}{3}
$$

Tahanan pentanahan minimal $1 \Omega$ pada komunikasi sistem/data dan maksimum harga tahanan yang diijinkan $5 \Omega$ pada gedung / bangunan [10]. Menentukan nilai tahanan pentanahan bangunan menggunakan persamaan 8 :

$$
R=\frac{\rho}{4} \sqrt{\frac{\pi}{4}}
$$

\section{Analisis Data}

Data yang telah diolah untuk mendapat nilai daya dan energi listrik selanjutnya dilakukan analisa sebagai berikut:

a. Menghitung rugi daya 1 phasa dengan menggunakan persamaan $\Delta P=I^{2} \cdot R$ (watt) dan 3 phasa $\Delta P=\sqrt{3} \cdot I^{2} \cdot R$ (watt)

b. Menghitung beban arus R, S. dan T untuk tegangan 380 volt menggunakan persamaan

c. Menghitung jatuh tegangan dengan menggunakan persamaan $\Delta \mathrm{V}=\mathrm{I} \times \mathrm{Z}$

d. Menentukan besar kapasitas sistem pengaman Gedung Fakultas Ekonomi Universitas Lancang Kuning

\section{Hasil Dan Pembahasan}

\section{A. Gedung 1 Fakultas Ekonomi Universitas Lancang Kuning}

Perhitungan pemakaian beban pada Fakultas Ekonomi Universitas Lancang Kuning menggunakan tabel 1 dengan pemakaian beban $\mathrm{R}=34$ amper, beban $\mathrm{S}=38$ amper dan beban $\mathrm{T}=33$ amper. Perhitungan pemakaian beban 3 phasa dapat dihitung sebagai berikut:

$$
\begin{aligned}
\text { I Rata }- \text { rata } & =\frac{\mathrm{I}_{\mathrm{RT}}+\mathrm{I}_{\mathrm{TS}}+\mathrm{I}_{\mathrm{TR}}}{3} \\
& =\frac{35+38+33}{3} \\
& =\frac{106}{3} \\
& =35,3 \text { amper }
\end{aligned}
$$

Besar pemakaian daya total dengan faktor daya maksimal 0,98 dengan kapasitas transformator sebesar $100 \mathrm{kVA}$ sebagai berikut :

$$
\begin{aligned}
\mathrm{P} & =\mathrm{KVA} \times \operatorname{Cos} \varphi \\
& =100 \times 0,98 \\
\mathrm{P} & =98 \mathrm{~kW}
\end{aligned}
$$

Jatuh tegangan yang terjadi di Fakultas Ekonomi Universitas Lancang Kuning sebesar dengan impedansi kawat $95 \mathrm{~mm}^{2}=0,3396+\mathrm{j} 0,3449$

$$
\Delta \mathrm{V}=\mathrm{I} \times \mathrm{Z}
$$

Maka besar jatuh tegangan sebagai berikut :

$$
\begin{aligned}
\Delta \mathrm{V} & =\mathrm{I} \times \mathrm{Z} \\
& =35,3 \times 0,605 \\
\Delta \mathrm{V} & =21,36 \text { volt }
\end{aligned}
$$

Nilai tahanan (R) kabel twistead ukuran $95 \mathrm{~mm}^{2}=$ 0,605 ohm-meter dapat di hitung rugi daya :

$$
\begin{aligned}
\Delta \mathrm{P} & =\mathrm{I}^{2} \times \mathrm{R} \\
& =(35,3)^{2} \times 0,605 \\
& =1246,1 \times 0,605 \mathrm{watt} \\
& =753,89 \mathrm{watt} \\
\Delta \mathrm{P} & =0,754 \mathrm{~kW}
\end{aligned}
$$

Pada bangunan nilai tahanan pentanahan dapat di hitung :

$$
\begin{aligned}
R & =\frac{\rho}{4} \sqrt{\frac{\pi}{4}} \\
& =\frac{100}{4} \sqrt{\frac{3,14}{4}} \\
& =22,15 \mathrm{ohm}
\end{aligned}
$$

Berdasarkan hasil perhitungan di peroleh besar arus rata rata pada tegangan 3 phasa 380 volt sebesar 35,3 amper, besar kapasitas daya sebesar $98 \mathrm{~kW}$, besar jatuh tegangan sebesar 14,4 volt, besar rugi daya sebesar 753,89 watt $(0,754 \mathrm{~kW})$ dan besar nilai tahanan pentanahan sebesar 22,15 ohm. Dari pembahasan di peroleh besar nilai pengukuran tahanan pentahanan titik kawat sebesar $66 \mathrm{ohm}$ dan 
tahanan pentanahan pada titik netral sebesar $52 \mathrm{ohm}$ melebihi nilai perhitungan pada analisa pembahasan tahanan pentanahan sebesar 22,15 ohm.

\section{B. Gedung 2 Fakultas Ekonomi Universitas Lancang Kuning}

Perhitungan pemakaian beban pada Fakultas Ekonomi Universitas Lancang Kuning menggunakan tabel 1 dengan pemakaian beban $\mathrm{R}=15$ amper, beban $\mathrm{S}=19$ amper dan beban $\mathrm{T}=14$ amper. Perhitungan pemakaian beban 3 phasa dapat dihitung sebagai berikut:

$$
\begin{aligned}
\text { I Rata }- \text { rata } & =\frac{\mathrm{I}_{\mathrm{RT}}+\mathrm{I}_{\mathrm{TS}}+\mathrm{I}_{\mathrm{TR}}}{3} \\
& =\frac{15+19+14}{3} \\
& =\frac{48}{3} \\
& =16 \text { amper }
\end{aligned}
$$

Menghitung pemakaian daya pada gedung Fakultas Ekonomi Unilak dengan besar pemakaian daya total dengan faktor daya maksimal 0,99 dengan kapasitas transformator sebesar $100 \mathrm{kVA}$ sebagai berikut :

$$
\begin{aligned}
\mathrm{P} & =\mathrm{KVA} \times \operatorname{Cos} \varphi \\
& =100 \times 0,99 \\
\mathrm{P} & =99 \mathrm{~kW}
\end{aligned}
$$

Menghitung rugi-rugi daya pada sistem kelistrikan Fakultas Ekonomi Unilak dengan impedansi kawat $95 \mathrm{~mm}^{2}=0,3396+\mathrm{j} 0,3449$

$$
\Delta \mathrm{V}=\mathrm{I} \times \mathrm{Z}
$$

Maka besar jatuh tegangan sebagai berikut :

$$
\begin{aligned}
\Delta \mathrm{V} & =\mathrm{I} \times \mathrm{Z} \\
& =16 \times 0,605 \\
\Delta \mathrm{V} & =9,68 \text { volt }
\end{aligned}
$$

Menentukan perhitungan rugi daya untuk kabel twistead ukuran $95 \mathrm{~mm}^{2}=0,605$ ohm-meter, maka diperoleh :

$$
\begin{aligned}
& \Delta \mathrm{P}=\mathrm{I}^{2} \times \mathrm{R} \\
& =(16)^{2} \times 0,605 \\
& =256 \times 0,605 \text { watt } \\
& \Delta \mathrm{P}=154,9 \text { watt } \\
& \Delta \mathrm{P}=0,155 \mathrm{~kW}
\end{aligned}
$$

Mengevaluasi Sistem Pentanahan Pada Gedung Fakultas Ekonomi Unilak menggunakan persamaan dibawah ini :

$$
\begin{aligned}
R & =\frac{\rho}{4} \sqrt{\frac{\pi}{4}} \\
& =\frac{100}{4} \sqrt{\frac{3,14}{4}} \\
& =22,15 \mathrm{ohm}
\end{aligned}
$$

Berdasarkan hasil perhitungan di peroleh besar arus rata rata pada tegangan 3 phasa 380 volt sebesar 16 amper, besar kapasitas daya sebesar $99 \mathrm{~kW}$, besar jatuh tegangan sebesar 9,68 volt, besar rugi daya sebesar 154,88 watt $(0,155 \mathrm{~kW})$ dan besar nilai tahanan pentanahan sebesar 22,15 ohm. Sedangkan besar nilai pengukuran tahanan pentahanan titik kawat sebesar $26 \mathrm{ohm}$ lebih besar dari nilai perhitungan dan tahanan pentanahan pada titik netral sebesar $21 \mathrm{ohm}$ lebih baik dari nilai perhitungan tahanan pentanahan sebesar 22,15 ohm.

\section{Kesimpulan}

Berdasarkan hasil pembahasan diperoleh evaluasi pada gedung Fakultas Ekonomi Unilak besar arus rata rata pada tegangan 3 phasa 380 volt sebesar 51,3 amper, besar kapasitas daya sebesar $197 \mathrm{~kW}$, besar jatuh tegangan sebesar 24,1 volt, besar rugi daya sebesar 908,8,89 watt $(0,909 \mathrm{~kW})$ dan besar nilai tahanan pentanahan sebesar 22,15 ohm.

\section{Daftar Pustaka}

[1]. As Pabla, 1994, Sistem Distribusi Daya Listrik, Erlangga, Jakarta.

[2]. Abrar Tanjung, Arlenny, 2015, Analisis Kinerja Sistem Kelistrikan Fakultas Hukum Universitas Lancang Kuning Pekanbaru, Jurnal Teknologi, Vol. 8 No. 1 Fakultas Teknologi Industri Institut Sains \& Teknologi Apkrind Yogyakarta. ISSN 1979-3405

[3]. Abrar Tanjung, 2015, Analisis Sistem Pentanahan Transformator Distribusi Di Universitas Lancang Kuning Pekanbaru, Jurnal SITEKIN UIN Susqa, Vol. 12 No. 2, Pekanbaru, ISSN 2407-0939 (On Line).

[4]. Abrar Tanjung, 2015, Analisis Kinerja Sistem Kelistrikan Akibat Penambahan Gedung Fakultas Keguruan Ilmu Pendidikan Universitas Lancang Kuning, Jurnal UNITEX Vol 12 No.2 Juli-Desember 2019, STT Dumai.

[5]. Abrar Tanjung, 2017, Reconfiguration Of Power Supply System 20 kV Distribution To Compare Power Rate And Fall Voltage PT. PLN (Persero) Area Dumai, IOP Conf. Series: Earth and Environmental Science 97 (2017) 012048, 
International Conference on Environment and Technology (IC-Tech) 2017

[6]. Samsul Bahraen, Sultan, I Made Ari Nrartha, 2018, “ Evaluasi Sistem Instalasi Listrik Di Gedung B Kampus Fakultas Teknik Universitas Mataram “, Jurnal Teknik Eletro ITP,. Volume 2 No 1, Mataram

[7]. Surya Darma, 2012, Analisis Pengaruh Ketidakseimbangan Beban Terhadap Arus Netral Dan Losses Pada Trafo Distribusi 200 $K V A$, Jurnal Teknik Elektro, vol 1 nomor 2 Februari 2012, ISSN 2089-2942
[8]. Ikrul Sadi, 2014, Keseimbangan Beban Pada Instalasi Listrik Di Gedung Riset Tsunami, Universitas Syiah Kuala Banda Aceh.

[9]. Zuhal, 1991, Dasar Tenaga Listrik, Penerbit ITB Bandung

[10]. Hutaruruk, 1991, Pengetanahan Netral Sistem Tenaga, Erlangga, Jakarta

[11]. Isaac Kofi Nti, Moses Teimeh, Owusu NyarkoBoateng \& Adebayo Felix Adekoya, 2020, Electricity load forecasting: a systematic review, Journal of Electrical Systems and Information Technology, volume 7, number 13. 